Near final version of paper published in: Mobilities 7(3): 389-414, 2012

Migration and Innovation at the Bottom End: Understanding the Role of Migrant Managers in Small Hotels in the Global City

Anna Paraskevopoulo, Working Lives Research Institute, London Metropolitan University

Eugenia Markova, Working Lives Research Institute and London Metropolitan University Business School, London Metropolitan University

Allan Williams, Surrey Tourism Research Centre, Faculty of Business Economics and Law, University of Surrey

Gareth Shaw, University of Exeter Business School 


\title{
Migration and Innovation at the Bottom End: Understanding the Role of Migrant Managers in Small Hotels in the Global City
}

\begin{abstract}
The paper examines the role of international migration and innovation in small hotels through a comparative study of migrant and non-migrant owners and managers in London hotels. The findings show the dependence of the sector on international managers whose contribution to innovation is understood in relation to the global environment of London, sectoral particularities and complex processes of mobility amongst both migrant and non-migrant managers. Although there is only limited evidence of differences in the levels or types of innovation, international migration is significant in the transfer and dispersion of knowledge, and plays a key role in the incremental innovation processes which are essential to innovation performance in the sector.
\end{abstract}

\section{INTRODUCTION}

International migration is acknowledged as an important dimension of innovation (NESTA, 2008) but most research focuses on what can be termed the 'high end' of knowledge intensive activities (for example, Saxenian, 1999, 2006). In contrast, the role of international migration in innovation in the 'bottom end', or less knowledge intensive, sectors such as hospitality, especially small businesses, has largely been neglected. Yet migrant owners and managers are a strong presence in many of the less knowledge-intensive service sectors, such as retailing, personal services and hospitality, in more developed countries. This paper focuses on whether international migrant managers (as opposed to migrant employee in general) contribute 
significantly to the intensity or types of innovation in one such sector, small hotels. If so, are they replacement or substitute managers, largely replicating the innovation performance of indigenous managers in a sector largely characterised by incremental or imitative innovation, or are they the source of different forms of incremental, or perhaps radical innovation? If entrepreneurs are 'heroic' figures in the landscapes of capitalism (Galbraith, 1969; Schumpeter, 1934), then are international migrants a largely unsung cohort of innovation in particular places - in this instance, - London?

The research is based on a case study of London. The findings emphasise the highly contingent nature of the contribution of migrant managers to innovation, being shaped by both the status of London as a global city, along with high and complex levels of mobility amongst both migrant and non-migrant managers. There is widespread recognition that migrants are important in the hospitality labour force in London, accounting for $60 \%$ to $80 \%$ of all employees (Anderson \& Ruhs, 2008). Less well known is the dependence of this sector on international managers and owner managers: some $70 \%$ of hotel managers in our sample were international migrants, originating from a variety of countries. They potentially play a pivotal role in shaping innovation in this bottom end sector. Are they a source of uncommon knowledge (Bentley, 1998) and therefore of different forms or innovation, or even of radical as opposed to incremental innovation (Sundbo, 1997)? Or do they largely replicate the innovation contribution of non-migrant managers, indicating that overall innovation performance is shaped by the structural characteristics of the sector, and the global city? These questions shine a new light on the fundamental issue of the relationship between competitiveness and productivity, and international migration.

The paper first explores some issues in the conceptualization of the role of migrants in innovation, focussing on both the hotel sector and small businesses, and then sets out the research methods employed. In the following section, we emphasise the need 
to deconstruct the notion of the migrant manager, and to focus on the migration experience in recognition of the complexities of national and international mobilities, in an increasingly mobile world. The fourth section compares the innovation perspectives of different groups of managers, focussing on different types of innovation as well as the relationship between innovation and firm performance. The conclusions consider some of the broader policy and theoretical implications of this research.

\section{MIGRATION, INNOVATION AND HOTELS: AN UNDER-RESEARCHED RELATIONSHIP}

\section{The Resource Theory of the Firm and the Role of Managers}

A starting point for considering the role of managers in innovation is the resourcebased theory (Barney, 1991) and especially the emphasis on one critical resource, knowledge (Wiklund \& Shepherd, 2003). Managers, and manager owners, possess a reservoir of knowledge accumulated during the course of often diverse careers. Experience of entrepreneurship is itself a source of knowledge (Rae, 2004), but this can be acquired in a range of environments (Holt \& MacPherson, 2006), including not only experience within the sector but also in other sectors. Both are of particular relevance in this paper, and of increasing importance in the face of enhanced human mobility, from having lived or worked in a different country.

Focussing for the moment on the acquisition of experiences and knowledge within the sector, a distinction is usually made between 'traditional' and 'modern' career paths (Harper, et al., 2005) into hotel management. The hotel industry has until recently maintained the more traditional approach, based on the "bureaucratic model of career development'. This follows a career ladder where the individual starts at the 
bottom and works his/her way up to the top depending on age, qualifications or experience (ibid). These traditional structures are increasingly being replaced by a different approach with the formalisation of training through a significant expansion in diploma, graduate and postgraduate level courses in tourism and hospitality. These courses tend to focus on more business related skills for managers (Gamble et al., 1994 and Rimmington, 1999).

A distinction however needs to be made between hotel management structures in medium/large hotels, which are often parts of national and international hotel chains, and in smaller hotels, usually with 2 stars or below - what would usually be considered to present low levels of knowledge intensity. There is still relatively little research on the latter, although the hotel industry in the UK, and in the $\mathrm{EU}$, is dominated by small and independent establishments (Morrison \& Conway, 2007). Career paths are less clearly defined in small hotels; many managers are owner managers, have inherited a family business, or have moved into hotel management from outside the industry. In smaller hotels, therefore, the management structure is more fragmented and career paths tend to be more dependent upon individual initiatives (Ladkin \& Riley, 1996). As a result, the profession attracts individuals from a range of backgrounds with diverse skills and work experiences, and consequently accumulated knowledge and innovation capacity. This diversity is reflected, in the heterogeneous approach of small tourism establishments to business planning, service provision, marketing and promotion (Thomas, 2000; Ram \& Smallbone, 2002). Another source of variation is the division of responsibilities (for strategic planning versus operations) between managers and owners, in those instances where the two functions are not combined in owner-managers. There is therefore no single management model in small hotels that frames innovation. Instead, individuals with diverse backgrounds become managers with some, and often significant, potential to influence innovation in particular businesses. One of the most substantial 
and surprisingly under-researched pathways within this picture of diversity - at least in major metropolitan areas - is international migration.

\section{Migration and Innovation}

While the role of international migration in tourism innovation has been noted (Hall and Williams, 2008, chapter 7), it has scarcely been researched, as is the case in most lower knowledge intensive sectors (Saxenian, 1999, 2006). We draw on two main perspectives to conceptualize this issue: knowledge transfer and the literature on ethnic SMEs (see Figure 1).

Smaller firms necessarily have fewer resources than medium or large companies, so they need to be especially effective in maximizing the effective use of their limited resources. Knowledge is considered a, if not the, critical resource (Wiklund \& Shepherd, 2003) in context of the resource-based theory (Barney, 1991) of the firm. Having relatively limited internal research and development resources, service firms are especially likely to source knowledge external to the firm (Lundqvist, 2005, Thorburn, 2005) from a variety of external sources ranging from suppliers to knowledge spill-overs (Arrow, 1962) via human mobility, including international migration. As emphasised earlier, individual knowledge is accumulated in many different settings (Holt \& MacPherson, 2006) both sectorally and territorially. Living or working in a different country is one means by which knowledge is acquired, and then transferred by international migration. Moreover, the experience of international migration per se can be a source of knowledge in terms of networking, and obtaining a comparative perspective on the nature of localised knowledge (Williams, 2006). International migration provides opportunities to acquire or transfer what Bentley (1998) terms 'uncommon knowledge' - that is knowledge which is different to that embedded in local knowledge systems in the destination. Studying or working 
abroad, an individual may acquire knowledge that is 'common' within that country, but uncommon in a different country. Being largely tacit, to some extent it can only effectively be transferred by international human (corporeal) mobility or migration (Williams, 2006).

Many different types of knowledge can be a source of innovation, both general managerial and country-specific. Individuals may have worked in hotels abroad with very different products, processes or management, and may be able to transfer knowledge of these to hotels in other countries. Alternatively, individual migrants may posses encultured knowledge (see Blackler, 2002) of consumer values, expectations and behaviour which can be a source for innovation for hotels receiving guests from those countries (Aitken \& Hall, 2000). Foreign language skills represent another form of uncommon knowledge. For example, writing specifically about internationalisation, but with broader resonance, Liesch et al (2002, p.24) comment that '... for smaller firms, foreign language proficiency among staff may be an important factor in determining how internationalisation is approached, including choice of country, and selection of agents or distributors'. Foreign language skills can unlock a wider range of contacts and more diverse market knowledge, much of which requires an understanding of culture and institutions that is what Blackler (2002) terms encultured or embedded knowledge. International migrant managers may, therefore, have potentially stronger access to a wider range of markets or international suppliers - as well as national sources - than non-migrants.

While we have focussed largely on international migration in this discussion, knowledge acquisition and transfer can be realised through diverse forms of human or corporeal mobility. For example, Loane et al. (2007, p.490) assert that the innovative behaviour of key decision makers in internationalised firms '... is often influenced by prior experience, in terms of international travel, being born abroad, 
having studied or worked overseas, access to global networks or foreign language capabilities'. We return to the importance of adopting a broader perspective on the nature of international mobility later in the paper.

A second, and different perspective, is provided by the literature on ethnic small businesses, although of course migrants only represent one element within ethnic minorities. There is a substantial literature on the ethnic small business, most of which makes no specific reference to innovation. Probably the best known example of this is Waldinger et al.'s (1990) 'interactive approach' which explains the distribution of ethnic enterprise in terms of the interactions between three types of opportunity structures (market conditions, access to ownership, and mediating government policy) and two types of group characteristics (predispositions to entrepreneurship, whether for positive cultural reasons, or blocked social mobility; and resources mobilization, including co-ethnic networks and collaboration). The most obvious connection to innovation is in terms of opportunities to access particular submarkets - that is, in terms of using the knowledge and networks of the migrant manager to target particular ethnic or national market segments. Resource mobilization - drawing on co-ethnic networks - may also enhance the capacity for implementing innovation; for example, in ensuring a supply of flexible and committed workers.

Although innovation is implicit in much of this literature, it is rarely explicitly addressed. This is most obvious in relation to the question of whether migrant and ethnic small firms can achieve 'break out' from their initial, often localised, focus on a particular ethnic (migrant) market segment. Innovation is implicit in breaking out into non-ethnic and, or non-local markets (Ram \& Jones, 1998). As explained later in the paper, the research methods employed mean that we can only partially capture the notion of break out in this study. 
Although this overview has provided insights into the relationship between international migration and mobility, it is also important to situate the research in context of London.

\section{London: innovation in a global city}

London is a global city and a hub for many different forms of international human mobility, ranging from short term business visits, through leisure and tourism flows, to long term migration and settlement. The economic opportunities and cultural features associated with being a 'Global' City have contributed to the significant diversity of London's population (Gordon et al., 2007), characterised by Vertovec (2006) as superdiversity. Not only can substantial tourism inflows be seen as an outcome of global city status, but tourism also contributes to preserving this status through sustaining English-language cultural events (Church \& Frost, 2004). In terms of the focus of this paper, two particular aspects need to be noted.

First, given the nature of its economy and tourism attractions, London experiences high levels of year-round demand which translates into exceptionally high occupancy rates and, periodically, into acute shortages of accommodation. In the last quarter of 2009, the average occupancy rate had reached $82.5 \%$ in the city (View London website 2010), which is consistent with an estimate of $84.1 \%$ for the third quarter of the same year (Deloitte, 2009). This is articulated in relatively strong prices, even compared to many other world cities, although subject to fluctuations relating to the strength of sterling and particular crises. The impact of a strong level of demand on innovation can be read in two ways. Either as fostering innovation, through enhancing confidence and positive expectations of returns on investment, or reducing the competitive pressures that contribute to innovation. 
Secondly, the hospitality sector has been identified as a major employer for migrant workers (Lucas \& Mansfield, 2008) at all levels. The sources have changed over time, with hospitality employers relying particularly on Eastern European $\mathrm{A} 8^{1}$ countries in the second half of the $2000-10$ decade. (People $\left.1^{\text {st }}, 2009\right)$. There is a long history of migrant employment in the hospitality industry in the UK, and more generally in Europe. Traditionally concentrated in urban areas, the migrant workforce is now more widespread in non urban and less culturally diverse places (Baum, 2007, Warhurst et al. 2006). However, London remains dominant and Gordon et al. (2007), based on the Annual Population Survey, suggest that over $60 \%$ of the jobs in hotels/restaurants and domestic services are filled by migrant workers. There are several reasons for this, including flexible working hours, seasonal recruitment, recruitment practices which are often based on a word of mouth, availability of migrant labour and acceptance of precarious working conditions and wages that do not reflect the individual's skills and qualifications (Lucas \& Mansfield, 2008). Spence (2005) found that pay rates for migrants in London are lowest in hospitality, which partly explains the difficulties of recruiting British workers to this sector, and the high labour turnover (Lucas \& Mansfield, 2008).

Sassen's (2001) thesis of the dual labour market for international migrants in the global city is also relevant here: large numbers of migrants are required to fill low paid service jobs in the global city, with demand in part being generated by both tourists and highly skilled migrants. As will be seen later, the internationalization of the workforce also extends to hospitality management, and international (however defined) managers constitute a majority rather than a minority in London hotels.

\section{RESEARCH METHODS}


Secondary sources for the hospitality sector are relatively poor, and although it is included in the main data base for innovation, the Community Innovation Survey, this excludes establishments with less than 10 employees, and provides no information about international migration. Therefore, a survey questionnaire was designed and distributed to hotels across London including the central zone, and adjoining areas to the north, south, east and west. A total of 155 completed questionnaires were obtained, supplemented by 51 follow-up in-depth, face-to-face interviews. The primary focus of the research was on managers/owners of micro and small businesses, defined as having less than 10 and 10-50 employees respectively. Some medium and larger hotels, employing over 50 staff, were included for comparative purposes. Based on 151 usable responses on the question regarding the number of employees, 88 of the hotel sample belonged to the micro category, 45 to small hotel category and 18 to medium/larger hotel category.

In the absence of reliable and comprehensive lists of hotels, especially of smaller establishments, the first step was to identify the main clusters of hotels, based on commercial lists and internet searches. These were initially invited in advance, by phone or letter, to participate in the survey. Following, a poor response rate, the strategy was modified to cold calling on hotels, selected randomly within each cluster. The questionnaires were completed at that time or, exceptionally, at an agreed future date. However, pre arranged appointments were necessary for face to face interviews with medium sized and larger hotels. The survey first focussed on clusters of hotels in central London but, as these were exhausted, shifted to include inner London. Around 30\% of sample consists of hotels in London's central zone. The remaining $70 \%$ consists of $27 \%$ hotels in south London and $33 \%$ hotels in west London: the majority of south and west hotels are in close proximity to the central zone. Finally, $10 \%$ of hotels outside the central zone were located in north and east London. 
In terms of migration status, two different indicators were used in the questionnaire to capture the complexity of migration experience. Accordingly four different groups of managers were distinguished: first, managers born in the UK and with working experience only in the UK; second managers born in the UK but who have had some work experience abroad; third, managers that are of migrant background but whose first job and work experience have been in the UK and; finally managers of migrant background that also have had some work experience abroad. In addition, the questionnaire was also able to capture the UK born managers who are second generation migrants. All these categories were used in order to understand migration experience from wider point perspective and they are better explained in the section of migration experience.

This was a difficult group of respondents to access. Hotel managers, especially in micro hotels, were usually responsible for a range of tasks and had very demanding pressurised schedules. Moreover, the survey was conducted between September 2008 and March 2009, a period that coincided with severe economic downturn, and meant that hotel managers were under more intense pressures than usual. Therefore, some questionnaires were filled in under tight time constraints, and exceptionally one or two questionnaires were completed in the corridors of the hotels while accompanying the manager who was performing some of his/her duties. At other times, hotel managers were suspicious of the motives of the researchers, considering that they were spying on behalf of their competitors or the tax or local authorities. Even when they agreed to participate, a few managers/owners gave evasive responses to questions relating to the number of bedrooms, the number of hotels owned and the number of employees. Despite these difficulties, 155 questionnaires were completed, and while the vast majority provided usable information on all the main questions, a small number of respondents did not provide 
information for particular questions: this is variable, and is noted where appropriate. As would be expected, the follow up interviews encountered fewer obstacles, as they were with willing participants.

\section{MIGRATION AND MIGRATION EXPERIENCE IN A MOBILE SECTOR}

\section{Migrant managers: diversity and segmentation}

The analysis started with a traditional and, as will be seen, relatively simplistic definition of migration based on the country of birth of the manager/owner of the hotel. In our sample $63 \%$ owners/managers were born outside $\mathrm{UK}^{2}$. This is broadly similar to the proportion of migrants in the total labour force in the sector, indicating that even the higher levels of the occupational hierarchy (including owner managers) is highly internationalised. A number of features can be noted about this group of managers.

First, the migrant managers come from a wide range of countries: 46 in total, with only a few from any one country with the exception of the 14 from India ${ }^{3}$. Otherwise, migrant managers originate from a variety of countries including: Pakistan and China in Asia; Zimbabwe, Gambia and Egypt in Africa; Greece, Cyprus, Italy, France and the A8 countries in Europe. There were also small numbers of managers from Australia, the US and Latin America.

Secondly, the managers are not evenly distributed throughout the hotel sector, but are strongly segmented. All the mangers in the small number of 5 star hotels in the study, and $60 \%$ of those in 4 star hotels, were either white British born, or originated from more developed countries. In contrast, most of the managers in hotels with 3 
star or fewer originated from less developed countries. This tends to reflect the broader segmentation of the international labour force in London (Church \& Frost, 2004, p. 211).

Thirdly, it is difficult to provide a simple narrative to explain both the prevalence of international managers in the hotel sector, and the segmentation of British versus different groups of migrants between higher and lower quality hotels. The explanation can not be found in their educational and professional qualifications because there were no significant differences between migrants and British-born owners/managers in this respect: $48 \%$ of migrants, compared to $53 \%$ of British-born, had a degree in hospitality management or hospitality related subject. Instead, the starting point is the nature of management jobs in the lower quality hotels. These are often small establishments with relatively few employees. Unlike larger hotels, where there is little evidence of functional flexibility (Wood, 1997; Lockwood \& Guarnier, 1989), they tend to be characterised by both functional and numerical flexibility (see Rimmer \& Zappala, 1988) throughout the labour force (Wood, 1997; Shaw \& Williams, 2004, chapter 3). Managers in smaller hotels often have to undertake a variety of tasks, including some of the more routine operational jobs. Combined with relatively low wages, these jobs are significantly less attractive than those in larger and higher quality hotels, which have more rigid job demarcation and clearer career progression routes for managers:

"...we are a small hotel and I work as the manager, I take the bookings, do the accounts, make the orders, cook breakfast, answer the phone. There is also a part time housekeeper from Philippines who cleans the rooms and vacuum cleans the floors. But I also do some cleaning if we are too busy" (small hotel, British-born, female, central London) 
But why are most managers, in 3 star or below hotels not only migrants, but predominantly from less developed countries. At one level, the answer is relatively simple for, as Hudson (2001, p.200) argues, the social divisions that people bring with them into the labour force are structurally and collectively created. There is evidence that the recruitment of migrant workers and distribution of jobs in hospitality are influenced by stereotyped views of employers based on factors such as gender, age, race and nationality (McDowell, et al, 2007, Anderson \& Ruhs, 2008). However, for the small hotels in London this seems to be of secondary importance as more informal recruitment practices are in place: networks of family and friends, word of mouth and availability and readiness to accept the job appear to be important recruitment factors (People $\left.1^{\text {st }}, 2005\right)$. This was confirmed in several of our interviews, for example:

"I came here as a manager when the present owner took over the hotel. He is from Malaysia and I am also from Malaysia. My ethnic background was the main reason that I was invited in the job - together with my previous experience in the hotel sector" (small hotel, migrant, female, central London).

As the People $1^{\text {st }}$ report indicates, this only accounts for the recruitment of some managers. Others were recruited by word of mouth, or from the workforce, or - and perhaps more tellingly - because of 'readiness to accept the job'. That is, readiness to accept a relatively low paid but responsible post in a hotel located at the heart of a global city where accommodation and other living costs are very high. In such circumstances, as Sassen (2001) argues in respect of the dual migration hypothesis, indigenous workers are unwilling to accept (relatively) low paid jobs. Instead these are taken by migrants, either as hoped for stepping stones to better jobs (or to fund their studies) or because their 'frame of reference' is the lower wages paid in their countries of origin (Piore, 1979). 
Fourthly, in terms of gender there is also evidence that, as Hudson (2001, p.200) argues, people bring structurally-created social divisions with them into the labour force. Only just over a third (38\% - 49 out of 155$)$ of the hotel managers in our sample were women both from migrant and British-born background. This low percentage of women managers partly reflects the deep-rooted division of labour within the sector. Many of the lowest paid and lowest status jobs in hotels, in housekeeping and cleaning, are dominated by women (Lucas and Mansfield, 2008), who carry over the domestic notions of care and domestic chores into waged labour. It may also reflect male dominated traditional career routes within hotel management structures generally, as well as the traditional role of the hotel manager, which has been socially constructed as appropriate for men (Guerrier, 1986).

\section{The complexities of mobility: Migration experience}

While the classification of managers in terms of country of birth provides insights into both the number of non-UK born managers, and their labour market segmentation, this only tells part of the story of the internationalization of management. Hotels - and tourism generally - are highly internationalized sectors, characterised by high levels of mobility amongst the workforce at all levels (Williams \& Hall, 2002). Therefore, in context of London being a major hub of international migration, there is a need to deconstruct further the notion of migrant versus non migrant. Not surprisingly, a fuller examination of the questionnaire findings reveals a more complex picture of migration in London hotels as many British-born respondents also had international migration experiences. Table 1 presents a four fold classification of migrants and British-born, which also takes account of the location of their previous employment: 'British-born', 'British-born second generation'4, 'migrants that have work experience abroad' and 'migrants whose first work experience was in the UK'. 
International mobility is characteristic of both the British born and those born outside the UK, if working experience is also taken into account. Thus $46 \%$ of the British born non-second generation, and $38 \%$ of British born second generation immigrants had worked abroad. In contrast, the 'migrant' group (not born in the UK) divides into two distinct sub-groups. Of these, $46 \%$ had worked abroad prior to coming to the UK, while $38 \%$ had their first job in the UK. The latter includes both those who migrated to the UK as children, and individuals who came initially as students, and stayed on in the UK to work, or were working to pay for their studies. Or put differently, there is far less difference between the migrant and non-migrant group in terms of having worked abroad, than appears at first sight; $44 \%$ of the British born, compared to $55 \%$ of those born outside of the UK. Of the total of 131 respondents, only $15 \%$ had no previous migration experience - if this is indicated in terms of place of birth, employment, or - for the purpose of this table only - being a second generation immigrant (assuming relatively high levels if different forms of international connectivity).

The migration experiences of the UK-born managers were explored more fully in the in-depth interviews and revealed three main aspects regarding their mobility: working abroad, second generation experiences, and the importance of national as opposed to international mobility.

First, almost half the British-born managers had previous working experience abroad before taking up their current posts. Such experience was either a personal career or life style choice, for which there is considerable evidence in the tourism and hospitality industries (Uriely, 2001) or it was a requirement of working in medium/larger hotel chains, many of which encourage staff mobility within their training programmes. 
"I am white British and was born in Oldham. I hold a Bachelor Degree in Hospitality and have worked in the tourist sector for 25 years and 21 of these years are in a major hotel chain. I have worked mainly in the UK, but held posts abroad often during my training; the longest period of work abroad was in Canada. It was an integral part of my training to change hotels and countries every week. I think that this is the only way to gain the needed experience and skills for adaptation and orientation." (small hotel, Britishborn, female, west London).

Although relatively short periods of training abroad do not equate to traditional definitions of migration, even these can be invaluable periods for acquiring experience and knowledge of hotels in different economic and cultural settings, that is acquiring encultured and embedded knowledge (Williams, 2007).

Second, most if not all the second generation migrants who were born in Britain have what can be termed 'an indirect migration experience' through their family and kin networks. They often maintain ties with family members abroad, go to the parental country of origin to study the language or take a course (usually in hospitality), and often work face to face in the hotels with nuclear and extended family members who are first generation migrants. Moreover, these family businesses may also maintain close ties with the country of origin in order to attract clients from these countries. In some ways, this does not differ significantly from the differences of second generation migrants in ethnic enterprises in other sectors (e.g. Waldinger et al, 1990; Kloosterman \& Rath, 2003). These international 'ethnic' market linkages can be important for small firms, and potentially an important source of marketing innovation both for second generation and first generation migrants. 
"This hotel is a family business. My father owned it before me and I trust that my son will take it over. My father arrived from Cyprus to London in 1949. I and my brother were born in London. My father bought two hotels in the area; one of them belongs to my brother and this one to me. Some of our customers are from Greece. I have started to work in the hotel since 2000. Before the hotel I worked as a business analyst for a large company but I believe that my learning of Italian was the only asset for my current job. I am a British-born Cypriot and I am very proud for the Cyprus government initiative to support the Greek language education in the UK." (small hotel, migrant, female, central London).

However, whilst such examples exist, care should be taken not to exaggerate the extent to which marketing and demand are segmented along nationality or ethnic lines, as discussed later.

Third, migration experience is gained not only from international but also from intranational mobility. London attracts people, usually young, from other UK regions who either come to further their career development or to seek new life experiences (Bruegel, 2000). As with international migration, this provides an opportunity to obtain experience and knowledge in different settings. The city's multicultural society was often emphasised by respondents in this category.

"I am white British. I graduated from Manchester Polytechnic and hold a BA in hospitality. I worked in Newbury, Cambridge and many other places, mainly for a large hotel chain, but coming to London was always my goal and I was able to do it 15 years ago..... Why I wanted to come to London? Because of the buzz, I like capitals because they are just big, this is good for 
the business but also for the kind of lifestyle I prefer" (small hotel, British-born, male, central London).

There is not the same opportunity to obtain 'uncommon' knowledge (of say languages or consumer culture), but it may be possible to acquire other forms of knowledge. The different ways in which 'nationally' and 'internationally' acquired knowledge feeds through into innovation is beyond the scope of this paper, but emphasises the need to understand international migration in a broader mobility perspective.

To summarise, this section looked at the complexity of defining migration and made a distinction between migration defined by the country of birth and migration experience acquired either through travelling to another country to work, or migrating to Britain and finding a first job there, or being born in the UK as a second generation migrant, or even through national migration to London from another UK location. This is especially relevant to the hotel sector which attracts people from a range of backgrounds, with $85 \%$ of our sample having some form of migration experience in terms of a broader definition of mobility.

\section{MIGRATION EXPERIENCE AND INNOVATION PERFORMANCE}

There has been increasing interest in understanding changes in tourism and hospitality businesses through the lenses of innovation theory (Hjalager, 2001; Hall \& Williams, 2008). The classic definition of innovation comes from the writing of Schumpeter (1934) and, although most subsequent research has focussed on manufacturing (Cainelli et al, 2005), there has been growing interest in the service sector (Tether, 2004). However, even within the literature on service sector 
innovation, innovation in tourism and hospitality is considered to be significantly different, in some ways (Martinez-Ros \& Orfila-Sintes, 2009), not least because its market is highly mobile as well as requiring considerable face to face contact.

Innovation can be classified in different ways (Adams et al, 2006), including the degree of newness or novelty, the focus of the innovation, and the attributes of the innovation. In this study, we understand innovation in terms of how respondents identified changes introduced in what the firm produces, how it was produced (reflecting both process and organization) and, or the markets for which it is produced. We did not attempt to measure the actual impacts of individual innovations, their short versus long term impacts, or the distributional or welfare impacts of these changes within or beyond the establishment. The questionnaire survey also did not differentiate between innovations which were incremental versus discontinuous or radical (Schumpeter, 1934), and which were new to the firm versus new to the industry versus new to the market. In other words, we focussed on managers' evaluations of the changes in their particular business. In this, we broadly follow the approach of Orfila-Sintes \& Mattson (2009, p.381), considering innovation as being something 'which is either new, or significantly improved with respect to its fundamental characteristics, and this may be new only to the firm rather than to the sector or the market'. This is consistent with the dominance of incremental innovation in most hotels.

Before proceeding to the findings, we note that tourism is a sector with a poor reputation for innovation. In part this is because they remain largely 'hidden' (NESTA, 2007) in secondary data sources, which tend rely on traditional measures (Evangelista, 2000) such as R\&D, technology, knowledge transfers from universities and public bodies, and patenting. In contrast, innovation in hotels, in common with 
the service sector generally, tends to rely more on organisational changes, supply chain innovations, and marketing innovations (Tether, 2004).

A selective approach is adopted in order to simplify the analysis. Drawing upon the work of Jacob et al (2003) and Orfila-Sintes et al (2005), three dimensions of innovation in hotels are identified: products, processes and market/organisational (Sundbo \& Galloouj, 1998). The first dimension relates to product enhancement and differentiation, which aim to improve customer experiences by creating new combinations or sets of services (Norman, 1984), including more environmentally sustainable products (Williams \& Shaw, 1998). The second dimension, relates to the process of producing hotel products and services, especially but not only the introduction of IT which is considered an essential part of the management, operation, marketing and strategic development for hotels (Buhalis \& O'Connor, 2005). Thirdly, we consider markets and innovation, which provide a particular link to the conceptualization of the ethnic enterprise. Finally, we provide and overview of managers' perspectives on the impact of innovations on the hotels' performance. We do not discuss these types of innovation further, as the emphasis in this paper is on the contribution of migrant versus non migrant managers, rather than understanding innovation per se.

\section{Product Enhancement and differentiation}

The majority of hotels reported that changes had occurred in the hotel in the last five years, and the most important are shown in Table 2. They emphasise both the measures taken by individual hotels, and external changes. The latter indicates the dependence of the industry on changes such as fluctuations in demand resulting from terrorism, disruption to flights, or changing visa requirements. The two main foci of internal changes relate to IT and the refurbishment of different areas of the hotel; 
the former reflects the information intensity of hotel business (Orfila Sintes et al, 2005), and the scale of technological changes, while the latter reflects the fact that many, or even most, London hotels are housed in relatively old buildings.

There is a notable difference between the two groups in respect of two changes. A larger proportion of 'managers with migration experience' reported changes in refurbishment, while evaluations of IT were broadly similar. Care must be taken in interpreting the reasons for this. It could be argued that migrants may be relatively more likely to be innovative for the reasons explained earlier, but an alternative view is that they may simply be more likely to be working in hotels with fewer stars, that is of lower quality. In fact $70 \%$ of migrant managers did work in hotels with 2 or less stars. There is likely to be a greater imperative in such hotels to innovate through upgrading the hotel fabric especially as competition has increased with the introduction of low budget hotels. Alternatively, it may be argued that hotels with 2 or less stars are more likely to be poorly resourced (in terms of both turnover and size) and less likely to have the absorption capacity (Cohen \& Levinthal, 1990) or the resources (Wiklund \& Shepherd, 2003) to implement innovations. If the latter holds true, then the migrant managers' evaluation of changes in their hotels is even more remarkable.

In the in-depth interviews, the migrants suggested that these changes are necessary for "both structural and aesthetic reasons" (medium hotel, migrant, male, central London), "because the customers demand it "(small hotel, migrant, male, central London) or to "reflect the hotel's position as a corporate and business hotel centre" (small hotel, migrant, male, central London). British-born managers also talked about the value of refurbishing and upgrading the services of their hotel: "I would like to have more than 30 bedrooms and also buy a piece of land to create a garden for the 
summer and for the smokers. I would also like to transform the hotel into a museum of its era. The building is Victorian style and it used to be a hat factory. It would be interesting to change decoration and show its historical character." (small hotel, British-born, male, central London).

The other major area of difference between the two groups of managers was in relation to 'changes due to wider shifts in tourism'. This was mentioned far more frequently by managers without migration experience. Again, this could be related to the stars of the hotel, and this group being relatively more likely to be in hotels with more stars. Arguably, such businesses are more likely to have formal long term business planning, so that the managers are more accustomed to think in these broader terms. However, during the in-depth interviews, when interviewees had more time to explain their views, foreign born managers gave the same weight as British born managers to the overall situation affecting the hotel industry. Changes such as the forthcoming Olympics, the arrival of Eurostar in Kings Cross or the increase in international travel via low budget airlines were seen as having a positive impact: "the Eurostar has resulted in quite a lot of one-night stays, also get a few British who come down to catch the train. Also some people come and stay here to go to the British Library and study" (small hotel, British-born, male, central London). Other changes were seen as negative, such as the $7^{\text {th }}$ of July 2005 London bombings, the economic downturn, strict health and safety regulations or over zealous planning controls by councils: "The downturn affected our market strategy. But when it comes to prices, we couldn't accept that a 5 star hotel would 'dip into the 2 star market'. There is a huge decline of the Japanese clients - related to the economic policy but shoppers from the Arabic countries are still here". (small/medium hotel, migrant, female, West London) 
We complemented the general discussion of changes in the hotel, with a question about one specific area of product innovation that has received considerable attention recently that is environmental measures: these were specified in terms of recycling, water conservation and energy conservation (Table 3). Overall the proportions are relatively low in relation to recent governmental but also international campaigns in raising awareness about taking environmental measures both as individuals/households and as businesses. This is particularly so as many of these innovations are potentially cost reducing for the migrants, and offer economic returns whatever their commitment to the social return of environmental measures. Again responses differ according to the star of the hotel as hotels with more than 2 stars have been more innovative in all three areas of environmental measures compared to those with 2 stars or less. While water and energy measures were essentially issue for individual hotels, recycling was externally constrained, being largely dependent on the variable services provided by local councils. One small business hotelier noted in her interview: “We can't recycle as the local Council won't help us. The Council ignores us. Occasionally, we recycle newspapers and have to take them to recycling spots" (small hotel, British-born, male, central London). Other managers also raised their concerns about recycling and noted that better provision by the local councils is needed to support smaller businesses wishing to innovate in this area.

Turning to the influence of migration, there are two main points to note here. First, it is generally the case that British-born managed/owned hotels were more likely than migrant managed establishments to have implemented environmental measures. Migration status clearly is not associated with innovation in any simple way. Secondly, the disaggregated measures of mobility experience reinforce the impression that migration does not seem to be a driving force behind innovation, although the detailed picture is complex. The British born were more likely to be managers in hotels which were environmentally innovative if they did not posses 
migration experience: this was the case with recycling and energy, but not with water conservation. Amongst migrants, those whose first job were in the UK were more likely to be innovative than those whose first job had been abroad in only one area recycling - while their hotels were less innovative with respect to energy and water. A possible explanation is that it is an issue of resources, with migrant managers being disproportionately likely to work in hotels with fewer stars, which generally have limited innovation capacity.

\section{The introduction and upgrading of IT systems and the Internet}

IT is a key area of innovation in the service sector generally (Cainelli et al, 2005), as well as specifically in the hotel sector (Siguaw et al, 2000), and featured prominently in the participants' responses when talking about important changes in the hotel. However, IT innovation is a complex area, involving a range of applications (Sigala et al, 2004), and we have therefore attempted to capture some of the critical ones in a detailed section of the questionnaire. The findings are summarised in Table 4. We again differentiate between the four categories which capture migration experience, as opposed to migration status. Given that IT applications are so important and so widespread in hotels, it is perhaps to be expected that levels of innovation tend to converge. However, by asking about 13 different applications, it is also possible to identify some substantial differences between types of innovation, for example between the very high usage of web sites or selling rooms on the web $(83 \%$ for the first and $76 \%$ for the second) and yield management and restaurant management at the other extreme ( $51 \%$ and $21 \%$ respectively).

The benefits of IT were highlighted in the in-depth interviews with both migrants who and British born. Several migrants mentioned this as being the first-and-foremost change in their hotel: "The most important change is the introduction of Internet and booking online. When first introduced internet bookings they were $20 \%$ of the 
bookings, now they are 90\%" (small hotel, migrant, male, central London). Britishborn managers also considered the introduction of IT as beneficial to their hotel: "The most important change during the last years was the introduction of internet booking which has had an impact on everything. The system also allows to know everything about the guests, especially the regular guests (including the type of the preferred pillow), the guest feed-back can be collected on the day of departure, electronically" (medium hotel, British-born, female, West London).

Looking at migration experience in more detail (Table 4) presents a different perspective. There is broadly consistent pattern that those who have worked abroad are more likely to have innovated than those who have not. This applies in a comparison of both the British born, with or without migration experience, and of the migrants, whose first jobs were abroad versus in the UK. The differences are not enormous and for several IT innovations are only a few percentage points but in some applications they amount to a difference of some 30 percentage points. Therefore working abroad, as opposed o being born abroad does seem to make a real difference if the complete portfolio of IT innovations is considered.

\section{Nationality, markets and innovation}

Marketing innovations involve introducing of new or improved ways of marketing the products of a business, and potentially include pricing, promotional and other measures. Businesses have a particular incentive to target new market segments in saturated markets (Go and Pine, 1995). This provides a link to the literature on ethnic enterprises (Waldinger et al, 1990), wherein the ability to target ethnic market segments is one of the major influences on the emergence of these businesses. That literature mostly focuses on retailing, and small scale manufacturing, where the 
markets are typically found in ethnic enclaves in the destination country. There is virtually no reference to hotels in that literature.

Migrant status, or migration experience, both potentially produce tacit knowledge of particular national market segments. These advantages are articulated in terms of language competence, and cultural knowledge of customs, expectations and behaviour. These can be translated into marketing strategies both formal and informal, which may range from multi-lingual web sites and brochures, to using networks to attract individual customers. The question is whether such tacit knowledge is translated into marketing innovations, and successful outcomes in terms of attracting visitors.

In the questionnaires we asked managers to indicate both the percentage of their guests from abroad, and also the most important country of origin of those guests. The findings are summarised in Table 5. There are no substantial differences in the proportion of guests who are from abroad, when comparing the four migration experience groups. Instead, between $72 \%$ and $76 \%$ in all four groups rely on international guests for more than half their visitors. Due to the way in which the questionnaires were completed, it is not possible to systematically break down this data to individual countries of origin of the guests.

However, the qualitative interviews do reveal that sometimes there is a link between the nationality of the guests and the nationality and general background of the manager/owner, as well as his/her marketing strategies: "most guests come from the USA because I am also from the States and I know the American market. I provide the clients with all American comforts such as air-condition in all rooms, icemakers, orthopaedic mattresses, American guidebooks. We also have guests from Japan. We have a manager that speaks Japanese and offers services for Japanese guests: 
Japanese guides, bath tubs instead of showers, typical Japanese breakfast with noodles. I try to understand their needs and the cultural diversity. For example our third most popular group of guests is from Greece. A lot of the hospitals in the area have Greek patients and relatives use our hotel. We have a Greek receptionist so she can speak to them. We always try to speak the language of the customer and have dictionaries behind the desk as well as translation sheets" (small/medium hotel, migrant, male, central London). Similarly, a Spanish manager mentioned that most of her guests were from Spain, although the hotel used an agency for its marketing: "About 70\% guests are from abroad mainly Spain, Norway, Sweden, but there are also guests from Australia. This is because of the marketing system as we use an agency" (small hotel, migrant, female, Central London). An Irish manager also mentioned that Irish guests use that hotel although not as part of the tour operator deals they have which are instrumental in the Japanese and Australian markets: "Most of the guests are from Japan, Australia and Ireland which is due to the largest tour operators, who are working for Japan and Australia" (medium hotel, migrant, male, central London). Finally a small hotel owner/manager in the Kings Cross area mentioned her Italian connections: "I am second generation British-Italian. We are a small hotel and we have been here for three generations. Our guests are mainly from Italy as we have many connections with the country. I speak Italian and I took some hospitality classes in Italy" (small hotel, British-born second generation, female, central London).

In summary, neither migration status nor migration experience seems to be influential in shaping markets and marketing strategies. Instead, some three quarters of hotels have more than $50 \%$ of their guests from abroad, irrespective of the migration experience of the managers/owners. This reflects the strong and highly internationalised demand in London, whereby international tourism becomes the 'normalised' majority market that no hotel can afford to neglect, or at least is not 
affected by. There are some instances of migrant hotels owners targeting particular ethnic market segments, but not on the scale witnessed in other sectors such as retailing.

\section{An overview of innovations and their impact on the business}

Innovation is in part an articulation of the different experiences, knowledge and networks of those with and without migration experience. Understanding the economic impact of this requires considering the relationship between innovation and the hotel's performance. There has been considerable generic discussion of this issue, dating back to Schumpeter (1934), with subsequent empirical analyses providing broadly confirmatory evidence to support a positive relationship (Hall and Kramarz, 1998). Hoffman et al (1998) specifically argue that such a relationship generally exists for small and medium sized firms. However, there is almost no systematic research on this issue in respect of hotels, with the exception of Jacob et als (2003) work on the Balearic Islands, which found positive but often complex relations between innovation and different aspects of firm performance. These complexities are important because it can not simply be assumed that innovation automatically contributes to firm performance in a positive way. For example, unless IT innovation is carefully planned and implemented, the costs may outweigh the returns (McAdam and Reid, 2001).

Measuring the outputs of service sector firms is problematic (Preissl, 2000) and this was exacerbated in this study by the suspicious attitudes of many of the respondents. We did not therefore seek any quantitative evidence of either the general economic performance of the firm (turnover, profit etc) or of the links between innovation and performance. Instead, participants in the questionnaire were asked to rank the impact of different types of innovation (phrased as changes) on 
their business. The majority of respondents considered the changes to be positive or very positive, and Table 6 shows the distribution of evaluations in terms of migration experience.

The evaluations of change, across 10 different areas of the hotels' operations, provide a picture of relatively minor differences overall, as well as variations between types of activities. In order to provide an overall summary measure, we have simply summed and averaged the percentages across all 10 areas of change for each of the migration experience groups. The highest average is for migrants whose first job was in the UK: 82.1 per cent, followed by the British born without migration experience, at 80.4 per cent. The two groups with employment experiences abroad have lower averaged cumulative figures of 75.5 per cent for migrants and 73.3 per cent for migrants.

There are three main observations relating to this table. First, that most managers are positive about the impacts of change on the performance of the hotel, with the overall average only falling below $74 \%$ in the case of environmental sustainability measures. Secondly, while there are only relatively minor differences in relation to migration, those who have worked only in the UK are more likely than those with migration experience to be positive about these changes. It is not possible to know whether this reflects real differences in performance, as opposed to migrants being more critical because they have the advantage of comparing international standards. Thirdly while migrants whose first job was abroad have a relatively low assessment of the impact of changes on performance, this has to be seen against a background of most of the managers from hotels with fewer stars being migrants from less developed economies. We consider the implications of these, and the earlier, findings in more detail in the conclusion. 


\section{CONCLUSION}

This paper has sought to advance the emerging body of research on the economic impact of migration in three ways. First, by going beyond the usual focus on skills, and more recently on knowledge, to look at innovation - both different types of innovation and the impact of innovation on economic performance. Secondly, by focussing on one of the relatively neglected low knowledge intensive sectors in the 'bottom end' of the economy, as opposed to high tech, and other knowledge intensive sectors such as financial services. Thirdly, by looking at managers rather than employees in general, or those in the lower ranks of the occupational hierarchy, because their positions give them relatively privileged opportunities to advance innovation and effect changes in the establishment's performance. Moreover, in contrast to the relative concentration of previous research on intra-firm mobility and migration within transnational corporations (Beaverstock 2005; Williams 2006), the focus here is mainly on international managers in micro and small establishments.

This paper has also sought to relocate the focus of debates about the contribution of international migration, from just looking at migration status in terms of country of birth or nationality, to considering mobility instead. This is particularly important in a global city, such as London, and in the hospitality sector, both of which are characterised by high levels of mobility. Migration is a complex process and cannot always be defined according to the country of birth. Therefore, the concept of migration experience has been used in order to reflect other dimensions of what constitutes being a migrant and accumulating knowledge, social networks etc from this experience. The four categories used to describe migration experience were: 'British-born', 'British-born second generation', 'migrant with first job abroad' and 'migrant with first job in the UK'. Limiting the classification to four categories facilitates the presentation of a complex data set, but we acknowledge that other and more detailed understandings of migration experience are also possible, including 
the channels and duration of migration, and relationship to co-ethnics in the destination country.

Some two thirds of the hotels in this study have foreign born managers/owners - as well as employing migrants in other positions throughout the occupational hierarchy reflecting the general role of labour migration in a global city. This can be explained in two ways. First, in relation to the generally flexible recruitment of management, especially in smaller hotels. It is not necessary for managers in small hotels to have previous background experience in hotels, or any formal qualifications, to be employed in these positions. At the same time, many of the managerial posts in smaller establishments involve a high degree of functional flexibility (Rimmer and Zappala 1988), with the roles of overall co-ordination, training, marketing etc. often blurring into operational hands-on duties in areas such as reception, bookings, housekeeping duties and cooking breakfasts. Perhaps the key here is the notion of the dual labour market in the global city (Sassen 2001), with a substantial cohort of migrant managers being required to fill the lack of British managers willing and able to work for relatively low salaries in management jobs at 'the bottom end', especially given high housing and living costs.

In fact, any notion of a dual labour market is cut across by a further layer of segmentation in the management of London hotels. Whereas most of the managers in four and five star hotels (which also tend to have more professionalised and formalised career structures) are British born, or migrants from more developed countries, most of the managers in hotels with 2 stars or less, are migrants from less developed economies. Whether this reflects human capital differences, different migration histories, or processes of othering and discrimination is beyond the scope of this paper. 
Turning to the central concern of this paper, the relative innovation performances of those with different migration experiences, several differences were observed, although these are often muted and demonstrate no consistent pattern. Those who have worked abroad, whether British or foreign born, were more likely to have a wider range of IT applications in their hotels. They are also more likely to emphasise the importance of refurbishment as an area of change. In contrast, the British born (without migration experience) were the most likely to have innovated in relation to two out of three areas of environmental measures. They were also more likely to be positive about the impacts of a range of changes (innovations) on the performance of the firm.

In terms of the two theoretical perspectives as to why migrants may be more active or effective in innovation than non-migrants, we found no clear evidence to support either thesis. Regarding Waldinger et al's (1990) interaction model of ethnic enterprises, we found little to suggest that this accounted for either high levels of entrepreneurship or innovation in London hotels: not least, with very few exceptions, there was little evidence that niche ethnic or national markets were important for most hotels. Similarly there was little evidence that migrants' potential possession of uncommon knowledge (Bentley 1998) was translated into either more or different forms of, innovation compared to non-migrants.

These findings should not, however, be read as arguing that migrants do not play an important role in innovation in London hotels. This is a sector where radical or discontinuous innovation is rare, and where incremental and imitative innovation prevails. It is also a sector which faces strong, and mostly consistently strong levels of demand, so that competitive pressures are muted to a degree - keeping up with what other hotels have to offer is more important than seeking a competitive edge through radical innovation (new to the sector or market). That leads to the question of 
how managers/owner learn about innovation, and whether international migration is important in this. It is in fact a highly internationalized sector in terms of both capital and labour. Transnational companies play an important role in the sector, and there is also a very high level of mobility of personnel at all levels of the occupational hierarchy. There are therefore multiple channels for international learning, and best practices and innovations are disseminated quickly across borders in an industry where the protection of property rights in innovation is weak (Hall and Williams 2008). There are therefore considerable similarities in the learning opportunities available to both migrants and non-migrants in terms of innovation. However, while the direct contribution of migrants to innovation in particular hotels may not appear distinctive, their role in the general transfer and dispersion of knowledge, within a broader internationalization context is important. They also play an important substitution or replacement role in the innovation process. Even the most mundane of innovations need to be managed when introduced into a hotel, and this role increasingly has fallen to those who are migrants and or who have experience of working abroad. This is especially notable in the lower stars hotels. Migrants and migration experience is therefore essential to maintaining, if not radically challenging, the innovation performance in the sector.

Finally, tentative and suggestive as many of these conclusions are, they do point to the need to develop other theoretical perspectives with which to address findings about innovation and migration in this sector. In particular, there is a need to rethink the implications of migration policies for innovation. Innovation in hotels in a global city is highly dependent on migrant managers, whether in initiating changes (which sometimes may come from the separate owners) or in implementing these. Many of these individuals did not specifically enter the UK to become managers in the hospitality sector, and to some extent they can be considered accidental or unintended entrepreneurs and innovators. Migration policies in the UK, as in many 
other countries (McLaughlan and Salt 2002) generally fail to capture the importance of innovation as opposed to skills. Moreover, they are increasingly based on points systems which are sectorally specific. Even if they prioritise hotels, they fail to recognize the accidental routes of many managers and entrepreneurs into the sector. In short, migration policies are often innovation blind, especially at the' bottom end' of the economy.

\section{Notes}

1. A8 countries refers to Eastern European countries that became members of the EU in 2004 EU enlargement. These include: Czech Republic, Estonia, Hungary, Latvia , Lithuania, Poland, Slovakia, Slovenia

2. This was based on 133 usable responses to this question

3. India and Bangladesh have long been a source of employees for multinational tourism corporations, reflecting, in part, the United Kingdom's imperial past (McDowell, et al 2007)

4. Although individuals in the categories 'British-born' and the British-born second generation' share the same country of origin, they differ in terms of family backgrounds and networks, e.g. they are likely to still have close and living relatives in their parents country of origin. This potentially gives them more 'direct' access to another country's culture and society.

\section{Selected Bibliography}

Adams, R., Tranfield, D. and Denyer, D. (2006), Innovation Types: Configurations of Attributes as a basis for Innovation Classification, (London: AIM Working Paper in press)

Aitken, C., and Hall, C.M. (2000). Migrant and foreign skills and their relevance to the tourism industry, Tourism Geographies: an International Journal of Place, Space and the Environment, 2(3), pp. 66-86

Anderson, B. and Ruhs, M. (2008) A need for migrant labour? The micro-level determinants of staff shortages and implications for a skills-based immigration policy, (London: Migration Advisory Committee, report)

Arrow, K. J. (1962), Economic Welfare and the Allocation of Resources to 
Invention, in: R.R. Nelson (ed.), The Rate and Direction of Economic Activity, pp.609625 (New York: Princeton University Press)

Bagwell, S. (2006) UK Vietnamese businesses: cultural influences and intracultural differences Environment and Planning C: Government and Policy 2006, 24 (1), pp. $51-69$

Barney, J. (1991) Firm resources and sustained competitive advantage Journal of Management, 17(1), pp.99-120

Baum, T., Dutton, E., Karimi, S., Kokkranikal, J., Frances, D., Hearns, N., (2007) Cultural diversity in hospitality work, Cross Cultural Management: An International Journal, 14(3) pp. 229-239

Beaverstock, J. V. (2005), Transnational elites in the city: British highly-skilled intercompany transferees in New York City's financial district, Journal of Ethnic and Migration Studies 31(2): pp. 245- 268

Bentley, T. (1998) Learning beyond the classroom: Education for a changing world (London: Routledge)

Blackler, F. (2002). Knowledge, knowledge work and organizations, in: Choo, C. W. and Bontis, N. (Eds.), The strategic management of intellectual capital and organizational knowledge pp.47-62 (New York: Oxford University Press)

British Hospitality Association (2010) 'London hotels set for double-digit growth' http://www.bha.org.uk/details1.cfm?page=news\&section=indnews\&codeid=203323\& CFID=23576958\&CFTOKEN=99823265 (accessed 17/08/10)

Bruegel, I. (2000) The restructuring of London's labour force: migration and shifting opportunities, 1971-91, Area 32(1) pp. 79-90

Buhalis D., and O'Connor, P., (2005), Information Communication Technology Revolutionising Tourism, Tourism Recreation Research, 30(3), pp.7-16

Cainelli, G., Evangelista, R., and Savon, M. (2005), Innovation and economic performance in services: a firm-level analysis, Cambridge Journal of Economics, 30(3) pp. 435-58.

Church, A. and Frost, M. (2004) Tourism, the global city and the labour market in London, Tourism Geographies, 6(2) pp. 208-228

Cohen, W M and Levinthal, D A (1990) Absorptive capacity: a new perspective on learning and innovation, Administrative Science Quarterly 35(1) pp. 128-152

Crompton, R. and Sanderson, K. (1990), Gendered Jobs and Social Change, (London: Unwin and Hyman)

Deloitte (2009) Hotel market Economy, (London: Deloitte) 
Evangelista, H. (2000), Sectoral patterns of innovation in services, Economics of Innovation and New Technology 9(3) pp.183-221

Galbraith, J.K. (1969), The New Industrial State. (Harmondsworth: Pelican)

Gamble, P., Lockwood, A. and Messenger, S. (1994), European management skills in the hospitality industry, International Journal of Tourism Research, 1(3) pp. 167-93

Go, F. M., and Pine, R. (1995), Globalization strategy in the hotel industry. (London: Routledge)

Gordon, I., Travers, T., Whitehead, C. (2007), The impact of recent immigration on the London economy. (London: Corporation of London)

Guerrier, Y. (1986), Hotel management: an unsuitable job for a woman?, Service Industries Journal, 6(2) pp. 227-40

Hall, B. H. and Kramacz, F. (1998), Effects Of Technology And Innovation On Firm Performance, Employment, And Wages, Economics of Innovation and New Technology, 5(2-4) pp. 99 - 108

Hall, M., and Williams, A. (2009), Tourism and Innovation (London: Routledge)

Harper, S., Brown C, Irvine W (2005), Qualifications: a fast track to hotel general manager? International Journal of Contemporary Hospitality Management, Volume 17(1) pp. 51-64

Hjalager, A. (2002), Repairing innovation defectiveness in tourism, Tourism Management 23 (5) pp. 465-474

Hoffman, K., Parejo, M., Bessant, J. and Perren, L. (1998) Small firms, R\&D, technology and innovation in the UK: a literature review , Technovation, 18(1) pp. 3955

Holt, R., and MacPherson, A. (2006), Small firms, learning and growth: A systematic review and reconceptualisation, (London: ESRC AIM)

Hudson, R. (2001), Producing Places, (New York: Guilford Press)

Jacob, M. Tintore, J., Guilo, E., Bravo, M. and Julet, J. (2003), Innovation in the tourism sector: results from a pilot study in the Balearic Islands, Tourism Economics 9(3) pp. 279-297

Kloosterman, R. and Rath, J. (eds) (2003), Immigrant entrepreneurs: venturing abroad in the age of globalization, (Oxford: Berg)

Ladkin, A., Riley, M. (1996), Mobility and structure in the career paths of UK hotel general managers: a labour market hybrid of the bureaucratic model? Tourism Management, 17(6) pp.443-52

Liesch, P. W., Welch, L. S., Welch, D., McGaughhey, S. L., Petersen B., and Lamb, P. (2002), Evolving strands of research on firm internationalization: an Australian- 
Nordic perspective International Studies of Management and Organization, 32(1) pp. 16-35.

Loane, S., Bell, J. and McNaughton, R. (2007), A cross-national study on the impact of management teams on the rapid internationalisation of small firms, Journal of World Business, 42(4) pp. 489-504

Lockwood, A. and Guerrier, Y. (1989), Flexible working in the hospitality industry: current strategies and future potential, Journal of Contemporary Hospitality Management 1(1) pp. 11-16.

Lucas, R. and Mansfield, S. (2008), Staff shortages and immigration in the hospitality sector, (London: Migration Advisory Committee report)

Martínez-Ros, E. and Orfila-Sintes, F. (2009), Innovation activity in the hotel industry Technovation, 29 (9) pp. 632-641

McAdam, R. and Reid, R. (2001), SME and Large Organisation Perceptions of Knowledge Management: Comparisons and Contrasts, Journal of Knowledge Management, 5 (3) pp. 231-241

McDowell, L., Batnitzky, A. and Dyer, S. (2007), Division, Segmentation and Interpellation: the embodied labours of migrant workers in a Greater London hotel, Economic Geography, 81(1) pp.1-25

McLaughlan, G. and Salt, J. (2002), Migration policies toward highly skilled foreign workers, London: University College London, Migration Research Unit, Report to the Home Office

Morison, A., Conway, F. (2007), The Status of the Small Hotel Firm, The Service Industries Journal, 27(1) pp. 47-58.

NESTA (2007), Hidden Innovation: How Innovation Happens in Six Low Innovation Sectors, (London: NESTA)

NESTA (2008b), UK Global Innovation: Engaging with New Countries, Regions and People, (London: NESTA)

Norman, R (1984), Service Management. Strategy and Leadership in Service Businesses (New York: John Wiley \& Sons)

Orfila-Sintes, F., Crespi'-Cladera, R., \& Ros, E. M. (2005), Innovation activity in the hotel industry: evidence from Balearic Islands Tourism Management, 26(6) pp. 851865

Orfila-Sintes, F. and Mattson, J. (2009), Innovation Behaviour in the Hotel Industry, Omega: The International Journal of Management Science, 37(2) pp. 380-394

People 1st (2009), State of the Nation 2009, (London: People $1^{\text {st }}$ )

Piore,M.J. (1979), Birds of passage (Cambridge: Cambridge University Press)

Preissl, B., (2000), European Service Sectors, in Boden, M. and Miles, I. Services and the Knowledge Based Economy, (London and New York: Continuum). 
Rae, D. (2004), Practical theories from entrepreneurs' stories: discursive approaches to entrepreneurial learning, Journal of Small Business and Enterprise Development, 11(2), 195-202.

Ram, M., and Jones, T. (1998), Ethnic minorities in business, (Milton Keynes: Small Business Research Trust)

Ram, M. and Smallbone, D. (2002), Ethnic minority business policy in the era of the Small Business Service Environment and Planning C: Government and Policy, 20(2), pp. 235-249

Rimmer, M. and Zappala, J. (1988), Labour market flexibility and the second tier, The Australian Bulletin of Labour 14(4) pp. 564-91

Rimmington, M. (1999), Vocational education: challenges for hospitality management in the new millennium, International Journal of Contemporary Hospitality

Management, 11(4), pp. 186-91

Saxenian, A. (1999), Silicon Valley's New Immigrant Entrepreneurs, (San Francisco: Public Policy Institute of California)

Saxenian, A. L. (2006), The New Argonauts, (Cambridge, MA: Harvard University Press)

Sassen, S. (2001) The global city: New York, London, Tokyo, (New Jersey: Princeton University Press)

Schumpeter, J. (1934) The Theory of Economic Development, (Cambridge, Mass: Harvard University Press)

Shaw, G. and Williams, A. (2004) Tourism and Tourism Spaces, (London: Sage)

Sigala, M., Airey, D., Jones, P. and Lockwood, A. (2004) ICT paradox lost? A stepwise DEA methodology to evaluate technology investments in tourism setting, Journal of Travel Research 43(2) pp. 180-92.

Siguaw. J.A., Enz, C.A. and Namasivayam, K. (2000) Adoption of information technology in U.S. hotels: strategically driven objectives, Journal of Travel Research, 39(2) pp.192-200.

Spence, L. (2005), Country of Birth and Labour Market Outcomes in London. An Analysis of Labour Force Survey and Census Data. (London: Greater London Authority)

Sundbo, J. (1997), Management of innovation in services. Service Industries Journal 17(3) pp.432-455

Sundbo \& Gallouj (1998), Innovation as a loosely coupled system in services. SI4S Topical Paper N 4. (Oslo: STEP Group)

Tether, B. (2004), Do Services Innovate Differently?, (Manchester: University of Manchester, Discussion paper 66) 
Thomas, R. (2000), Small firms in the tourism industry: some conceptual issues, International Journal of Tourism Research, 25(5) pp.345-53

Thornburn, L (2005), Knowledge Management and Innovation in Service Companies - Case studies from Tourism, Software and Mining Technologies, Study for the department of Industry, Tourism \& Resources, (Australia: Innovation Dynamics), http://www.oecd.org/dataoecd/58/39/34698722.pdf (Accessed 3.11.10)

Uriely, N. (2001), 'Travelling workers' and 'working tourists': variations across the interaction between work and tourism, International Journal of Tourism Research 3(1) pp. 1-8.

Vertovec, S. (2006), The Emergence of Super-Diversity in Britain, Working Paper No. 25, (Oxford: Compas)

View London, http://www.viewlondon.co.uk/news/london-hotels-enjoy-recordoccupancy-levels-figur-19648436.html (Accessed 3.08.10)

Waldinger, R., Aldrich, H., \& Ward, R. (1990), Opportunities, group characteristics, and strategies in: R. Waldinger, H. Aldrich and R. Ward (Eds.), Ethnic entrepreneurs pp.13-48, (Newbury Park: Sage)

Warhurst, C., Nickson, D.,Dutton, E., Commander, J., James, S., and Lloyd, C. (2006), Low Wage Work in UK Hotels and the Institutional Policy Responses, (London: Russell Sage Foundation)

Wiklund, J. and Shepherd, D. (2003), Knowledge-based resources, entrepreneurial orientation, and the performance of small and medium-sized businesses, Strategic Management Journal, 24(1) pp. 1307-1314

Williams, A. and Shaw, G. (1998) Tourism and the environment: sustainability and restructuring', in C. M. Hall \& A. Lew (eds.). Sustainable Tourism: A Geographical Perspective $_{2}$ pp 49-60 (London: Longman)

Williams, A. (2006). Lost in translation? International migration, learning and knowledge. Progress in Human Geography 30(5) pp. 588-607.

Williams, A. (2007), Listen to Me, Learn with Me: International Migration and Knowledge Transfer, British Journal of Industrial Relation, 45(2) pp. 361-382

Williams, A. and Hall, C. (2002), 'Tourism, migration, circulation and mobility: the contingencies of time and place', in C. M. Hall and A. M. Williams (eds), Tourism and Migration: New Relationships between Production and Consumption, pp. 1-52 (Dordrecht: Kluwer)

Wood, R. C. (1997), Working in Hotels and Catering, (London: International Thomson Business Press) 
